\title{
Study on Concentrating Characteristics of a Solar Parabolic Dish Concentrator within High Radiation Flux
}

\author{
Qianjun Mao, ${ }^{1}$ Liya Zhang, ${ }^{1}$ and Hongjun $\mathrm{Wu}^{2}$ \\ ${ }^{1}$ School of Civil Engineering, Northeast Petroleum University, Daqing 163318, China \\ ${ }^{2}$ Provincial Key Laboratory of Oil \& Gas Chemical Technology, College of Chemistry \& Chemical Engineering, \\ Northeast Petroleum University, Daqing 163318, China \\ Correspondence should be addressed to Qianjun Mao; maoqianjun@163.com and Hongjun Wu; hjwu@nepu.edu.cn
}

Received 29 June 2015; Revised 25 August 2015; Accepted 30 August 2015

Academic Editor: Xudong Zhao

Copyright (c) 2015 Qianjun Mao et al. This is an open access article distributed under the Creative Commons Attribution License, which permits unrestricted use, distribution, and reproduction in any medium, provided the original work is properly cited.

\begin{abstract}
Concentrating characteristics of the sunlight have an important effect on the optical-thermal conversion efficiency of solar concentrator and the application of the receiver. In this paper, radiation flux in the focal plane and the receiver with three focal lengths has been investigated based on Monte Carlo ray-tracing method. At the same time, based on the equal area-height and equal area-diameter methods to design four different shape receivers and numerical simulation of radiation flux distribution characteristics have also been investigated. The results show that the radiation flux in the focal plane increases with decreasing of the focal length and the diameter of the light spot increases with increasing of the focal length. The function of the position with a maximum of radiation flux has been obtained according to the numerical results. The results also show that the radiation flux distribution of cylindrical receiver has the best performance in all four receivers. The results can provide a reference for future design and application of concentrating solar power.
\end{abstract}

\section{Introduction}

With the rapid development of global economy, the challenges for environment and energy are more and more important to the human. Concentrating solar power (CSP) is regarded as an effective way to solve energy problem $[1,2]$. The main idea of CSP is that the sunlight hits the surface of the earth and concentrates on the receiver, where the fluid is heated from the energy [3-6]. A large number of CSP projects have currently been developed or proposed in many countries, particularly in China, Spain, and USA. As we know, the concentrating characteristics of the sunlight in CSP plant have very huge effect on the efficiency and cost of the power. The concentrating types of CSP plant often have four contributions: solar power tower, solar parabolic dish, parabolic tough collector, and linear Fresnel reflector. Solar parabolic dish system has the best concentration ratio in all four types and the radiation flux has maximum. Therefore, the investigation of concentrating characteristics of a solar parabolic concentrator with a high radiation flux is very necessary and can provide a reference to the state-of-the-art design of CSP plant.

A large number of advancements have taken place in recent years in an effort to make radiation flux of the receiver more uniformly and effectively. As for the CSP system, there are some researches that focus on the solar radiation, conversion efficiency, and storage tank [7-9]. Ji et al. have experimentally investigated the application and the efficiency in solar optical-thermal and PV fields, that is, solar heating water and heat pump, and have obtained some important results [10-14]. Shuai et al. have applied the Monte Carlo ray-tracing method and coupled with optical property to simulate the performance of a solar parabolic dish system. They have proposed an upside-down pear cavity receiver based on the concept of equivalent radiation flux. The results show that uniformity performance of the wall flux is compared with five traditional geometries [15]. Clausing has presented an analytical model to calculate convective loss for a receiver. The analytical results and experimental evidence in the research have indicated that the convective 
loss for the receiver is appreciable $[16,17]$. Nithyanandam and Pitchumani have integrated the cost and performance model of an encapsulated phase change materials thermal energy storage and latent heat to study the dynamic thermal energy system performance [18]. Emes et al. have assessed the influence on the levelized cost of electricity of the design wind speed [19]. Desai and Bandyopadhyay have reported extensive energy and economic analysis of CSP plant [20].

In the above literatures, these researches focus on the energy conversion efficiency and the concentrating types, but the effect of the local length of parabolic dish and geometrical configuration of the receiver on the radiation flux and the system's efficiency is limited. In this paper, the concentrating ways of sunlight firstly have been established based on Monte Carlo ray-tracing method. After that, the effect of the local length on the radiation flux in the local plane and the receiver has been investigated. Finally, the effect of the geometrical configuration of the receiver on the radiation flux distribution has been simulated. The present study can provide a reference for the future design and application of CSP plant.

\section{Monte Carlo Ray-Tracing Method}

The Monte Carlo ray-tracing method, referred to as MCRT, is a popular tool with high accuracy in this field [21, 22]. Therefore, MCRT method has been employed for calculating radiation performance for all cases in present study. As we have known, the idea of this method is that the transfer process of the solar radiation is divided into four subprocesses, that is, emission, reflection, absorption, and scattering, and every subprocess has an occurrence probability [23-27]. The object of the study is divided into many surface units and mathematical functions can stand for them. The MCRT method used in this paper is to assume every surface emits a certain quantity of light rays, after which each ray is tracked and judged based on whether it is absorbed by the material, interface, or escapes from the system. In the numerical simulation, each sunlight ray carries the same amount of energy and has a specific direction determined from the appropriate probability function. What happens to each of these sunlight rays depends on the physical parameters of the materials of the system, which is described by a set of statistical relationships. The computer code for MCRT method has been written in FORTRAN language inhouse. The detailed description of this model can be inferred from the literature [3]. The outer surface of the receiver is considered to be adiabatic. The receiver is located at the focal plane of the parabolic dish system.

\section{Results and Discussions}

3.1. Effect of the Local Length on the Radiation Flux Distribution. In this study, the radiation flux distributions of the local plane and receiver within three local lengths, that is, $2500 \mathrm{~mm}, 3250 \mathrm{~mm}$, and $4000 \mathrm{~mm}$, have been obtained. In simulation process, the basic parameters are as follows: incident solar irradiation in the air is $1100 \mathrm{~W} / \mathrm{m}^{2}$, system error is $0 \mathrm{mrad}$, radius of the parabolic dish concentrator is $2600 \mathrm{~mm}$, height of the parabolic dish concentrator is $520 \mathrm{~mm}$, reflectivity of the parabolic dish concentrator is 0.9 , radius of the cylindrical receiver is $100 \mathrm{~mm}$, and height of the cylindrical receiver is $260 \mathrm{~mm}$.

Light spot performance of the local plane in different local lengths has been simulated and shown in Figure 1. It can be seen from the figure that the light spot is circle and radius of light spot increases with increasing of local length. The results show that the diameter of light spot is about $22.4 \mathrm{~mm}$ and radiation flux of light spot is about $30.46 \mathrm{MW} / \mathrm{m}^{2}$ when the local length is $2500 \mathrm{~mm}$. Meanwhile, the results show that the diameter of light spot is about $30.0 \mathrm{~mm}$ and radiation flux of light spot is about $21.80 \mathrm{MW} / \mathrm{m}^{2}$ when the local length is $3250 \mathrm{~mm}$. The results also show that the diameter of light spot is about $37.0 \mathrm{~mm}$ and radiation flux of light spot is about $18.58 \mathrm{MW} / \mathrm{m}^{2}$ when the local length is $4000 \mathrm{~mm}$.

$3 \mathrm{D}$ radiation flux distribution of the receiver in different local lengths has been simulated and shown in Figure 2. It is very obvious that the positions with the maximum flux are about $60 \mathrm{~mm}, 127 \mathrm{~mm}$, and $160 \mathrm{~mm}$ when the local lengths are $2500 \mathrm{~mm}, 3250 \mathrm{~mm}$, and $4000 \mathrm{~mm}$, respectively. It also can be found that the position with the maximum flux increases with increasing of local length. This distribution has indicated that local length has important effect on the concentrating characteristic of sunlight. When sunlight hits the wall of the receiver, almost all sunlight rays can be absorbed by the receiver.

Figure 3 shows the curve of the position along the wall, the diameter of light spot, and the radiation flux of light spot in different local lengths. It can be obtained from the figure that the optimal design is essential for the system. When the radius of the receiver is more than the radius of light spot, the sunlight can enter into the receiver. However, when the radius of the receiver is less than the radius of light spot, part of sunlight rays cannot enter into the receiver, which produces optical heat loss. According to the above results, the function of the position along the wall and the local length with an error of $5 \%$ can be proposed and given as follows:

$$
\begin{aligned}
\tan \theta= & 10.10-5.05 \times 10^{-3} \times p+0.67022 \times 10^{-6} \\
& \times p^{2},
\end{aligned}
$$

where $\theta$ is an angle of the axis direction of the receiver and inlet direction of the sunlight and $p$ is local length with unit of $\mathrm{mm}$. For this equation, it can only be used for the same concentrating system and the cylindrical receiver. Also, when the parameters of the concentrating system change, the results can accordingly be obtained from the computer code for MCRT method.

\subsection{Effect of Geometrical Configuration on the Radiation} Flux Distribution. To investigate the effects of the geometrical configurations on the radiation flux distribution, four receivers (i.e., frustum, inverted frustum, cylindrical, and conical receivers) shown in Figure 4 have been designed and simulated. The parameters of the receiver are given based on the equal area-height and area-radius method and shown in Tables 1 and 2, respectively. 


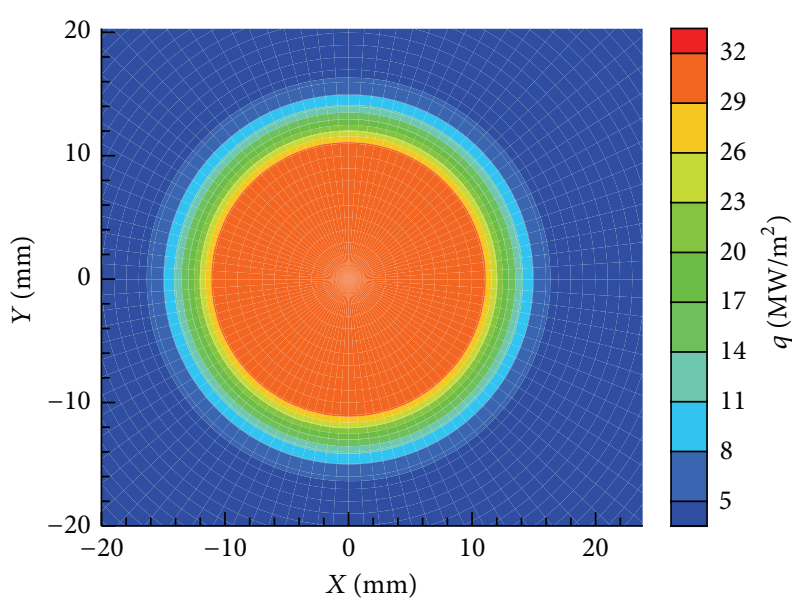

(a)

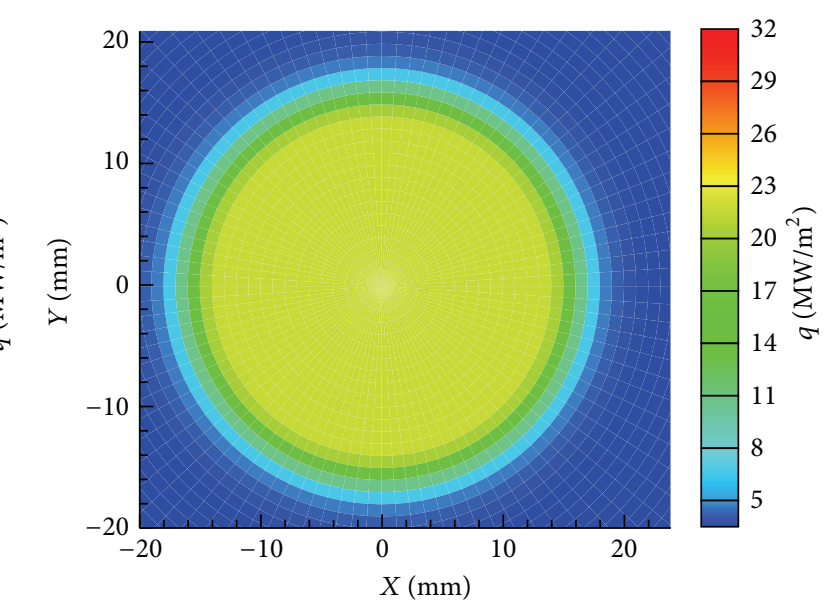

(b)

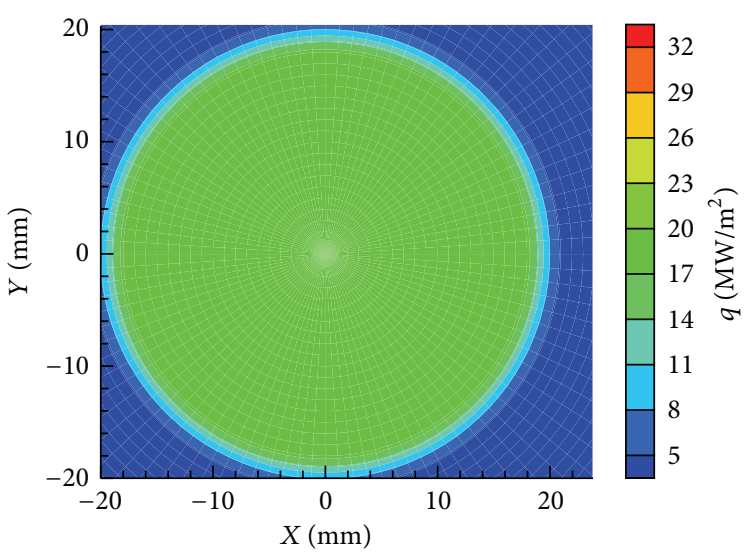

(c)

FIgURE 1: Radiation flux distribution in focal plane with different focal lengths: (a) $2500 \mathrm{~mm}$; (b) $3250 \mathrm{~mm}$; (c) $4000 \mathrm{~mm}$.

TABLE 1: Design parameters of the receiver based on equal areaheight method.

\begin{tabular}{lccc}
\hline Shapes & Height $(\mathrm{mm})$ & $\begin{array}{c}\text { Radius in the } \\
\text { bottom }(\mathrm{mm})\end{array}$ & $\begin{array}{c}\text { Radius in the } \\
\text { top }(\mathrm{mm})\end{array}$ \\
\hline Frustum & 260 & 120 & 78 \\
Inverted frustum & 260 & 78 & 120 \\
Cylindrical & 260 & 100 & 100 \\
Conical & 260 & 168 & 0 \\
\hline
\end{tabular}

Figure 5 shows the radiation flux distribution of the receiver based on equal area-height method. It can be seen from the figure that (1) the radiation flux is symmetrical along the circumferential direction; (2) the performance for the radiation flux distribution in the conical receiver is the worst; (3) the characteristics of the radiation flux distribution in the cylindrical receiver are similar to frustum and inverted frustum receiver.

Figure 6 shows the radiation flux distribution of the receiver based on equal area-radius method. It also can be seen from the figure that (1) the radiation flux is also symmetrical along the circumferential direction; (2) the
TABLE 2: Design parameters of the receiver based on equal arearadius method.

\begin{tabular}{lccc}
\hline Shapes & Height $(\mathrm{mm})$ & $\begin{array}{c}\text { Radius in the } \\
\text { bottom }(\mathrm{mm})\end{array}$ & $\begin{array}{c}\text { Radius in the } \\
\text { top }(\mathrm{mm})\end{array}$ \\
\hline Frustum & 235 & 100 & 120 \\
Inverted frustum & 285 & 100 & 80 \\
Cylindrical & 260 & 100 & 100 \\
Conical & 510 & 100 & 0 \\
\hline
\end{tabular}

performance for the radiation flux distribution in the conical receiver is the worst. All radiation flux almost focuses on the middle of the receiver and a little radiation flux in the top and bottom of the receiver; (3) the radiation flux distribution in the cylindrical receiver obviously priors to other receivers. For getting the higher efficiency of the system, the higher radiation flux is necessary for the receiver.

\section{Conclusions}

In this paper, radiation flux in the focal plane and the receiver with three focal lengths has been investigated based on 


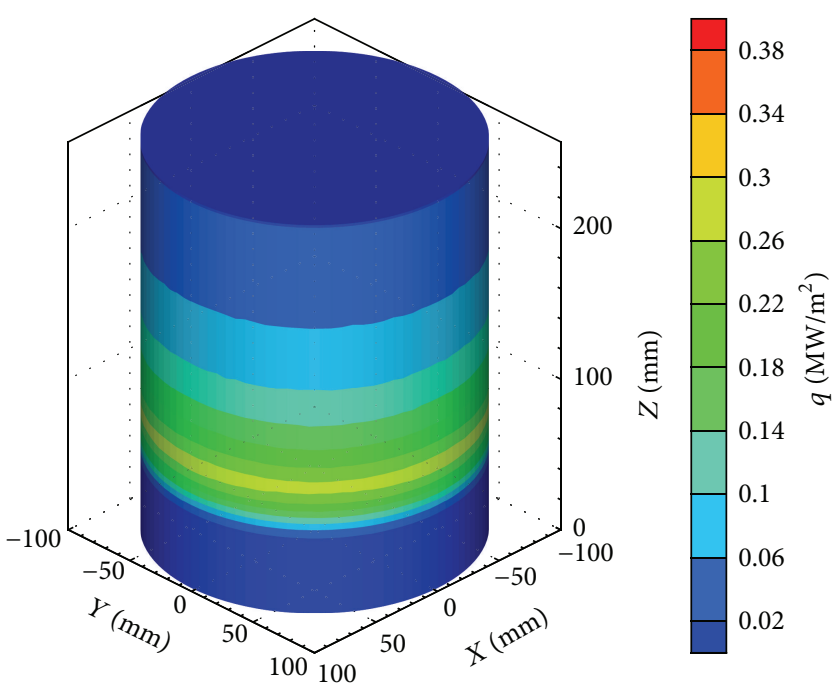

(a)

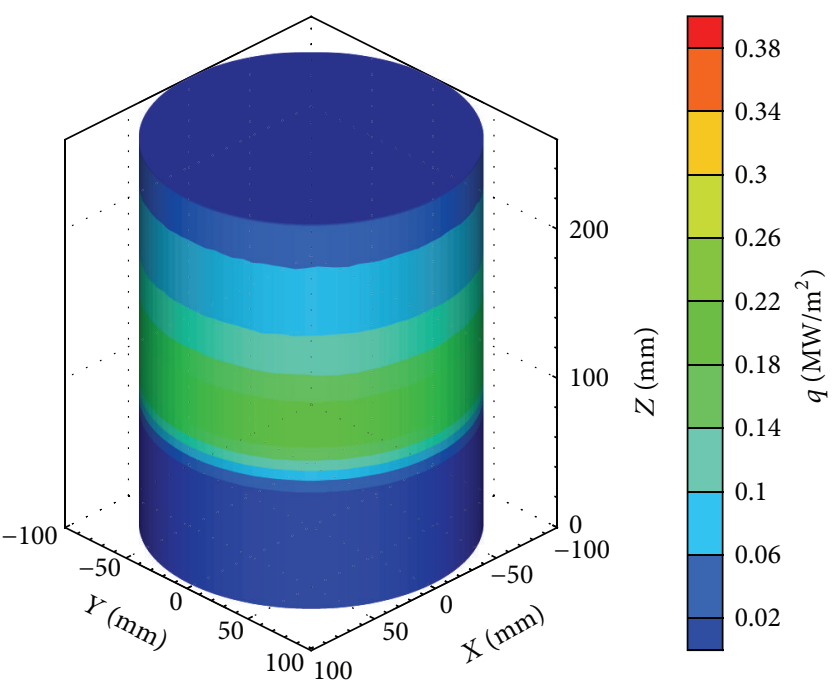

(b)

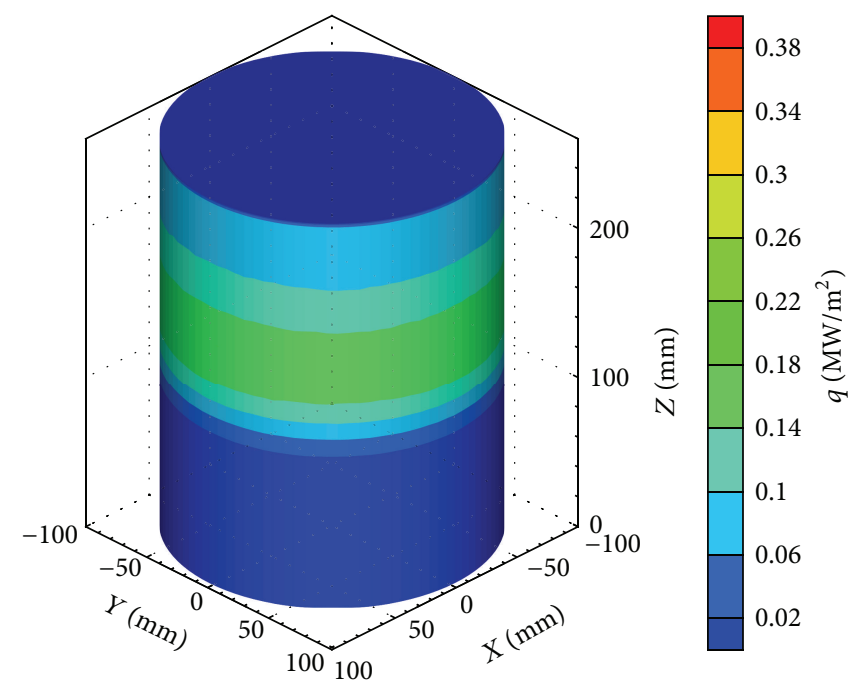

(c)

FIGURE 2: Radiation flux distribution in the receiver with different focal lengths: (a) $2500 \mathrm{~mm}$; (b) $3250 \mathrm{~mm}$; (c) $4000 \mathrm{~mm}$.

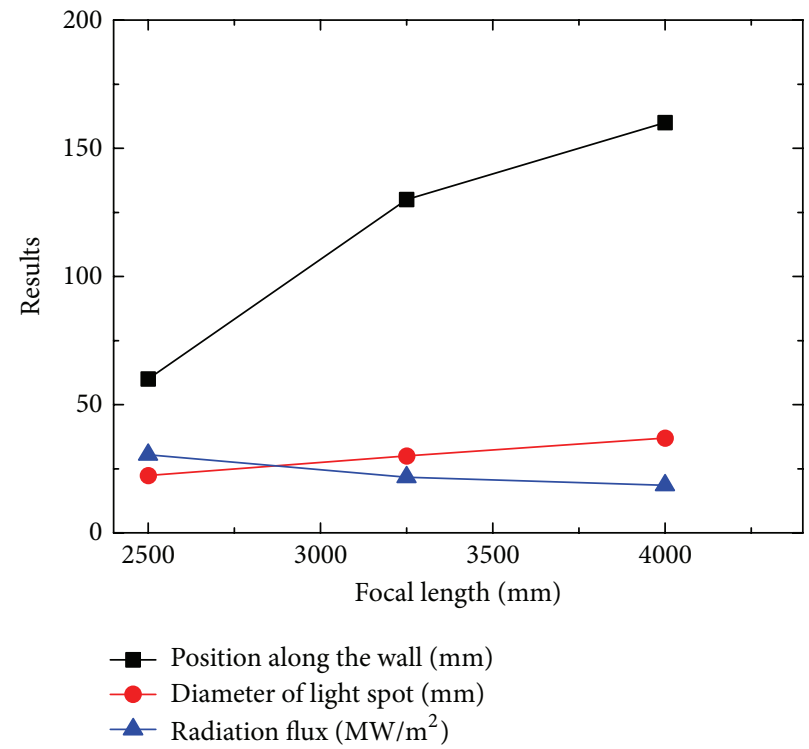

FIGURE 3: Effect of the focal length on the performance of concentrating characteristics. 


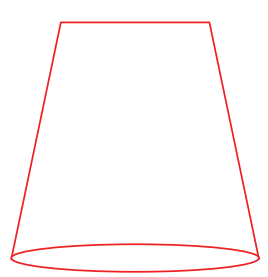

Frustum

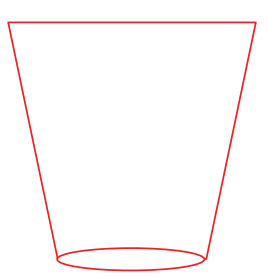

Inverted frustum

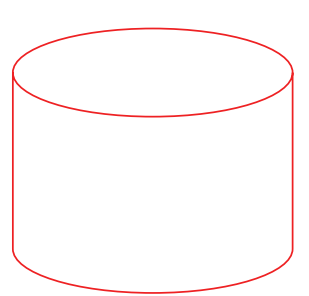

Cylindrical

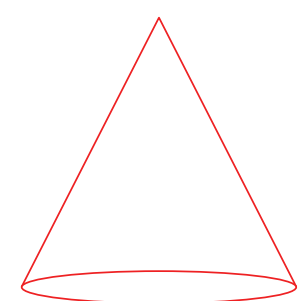

Conical

FIGURE 4: Four types of the receiver.

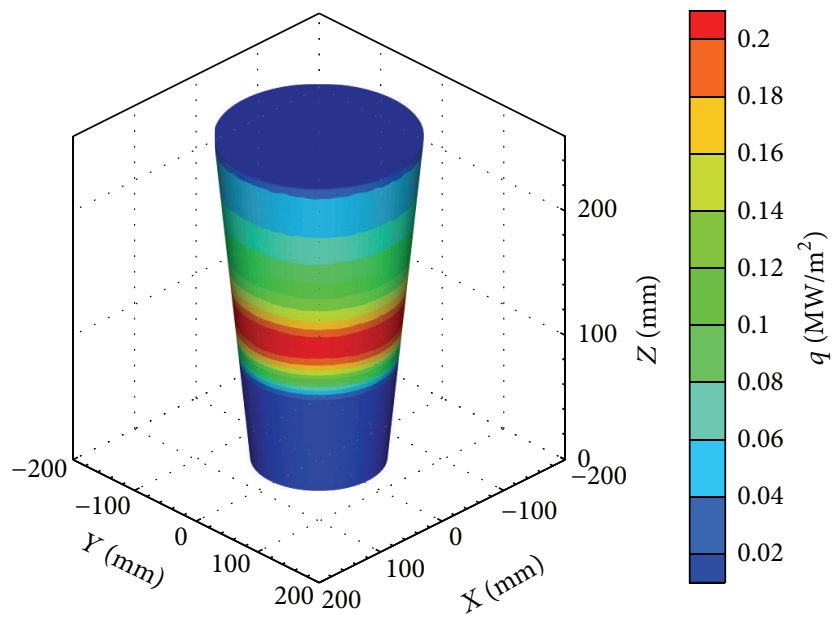

(a) Frustum

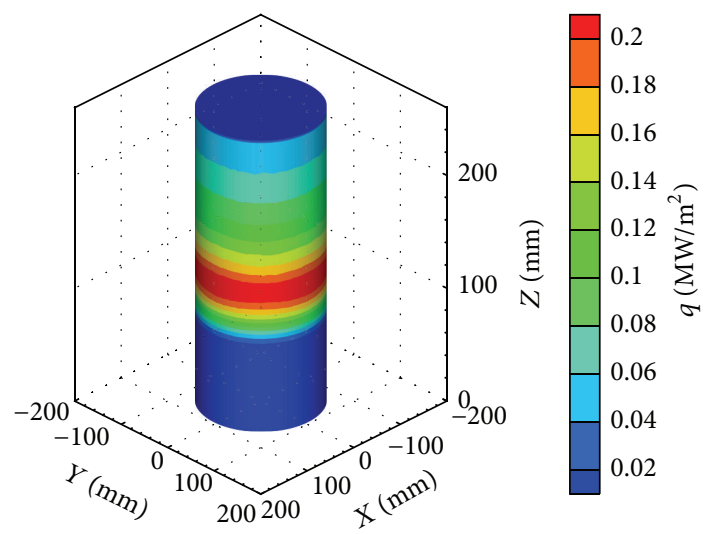

(c) Cylindrical

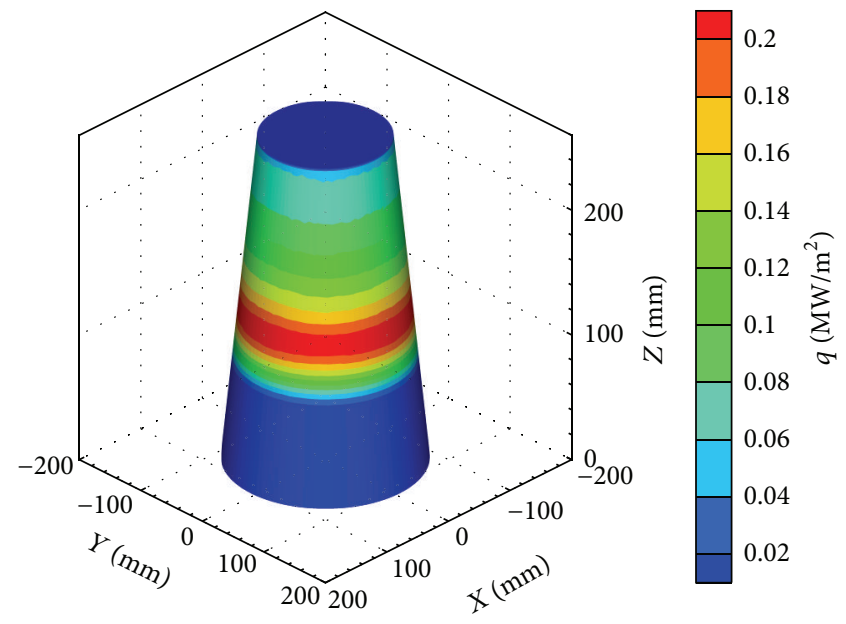

(b) Inverted frustum

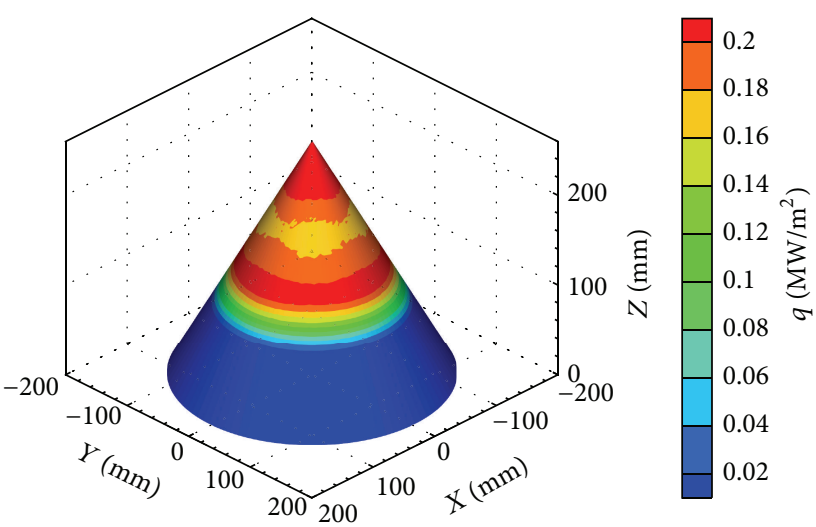

(d) Conical

FIGURE 5: Radiation flux distribution based on equal area-height method.

MCRT method. Also, four different shape receivers have been designed and simulated based on the equal area-height and equal area-diameter methods. The main conclusions can be given as follows:

(1) The radiation flux in the focal plane increases with decreasing of the focal length and the diameter of the light spot increases with increasing of the focal length.

(2) The positions with the maximum flux are about $60 \mathrm{~mm}, 127 \mathrm{~mm}$, and $160 \mathrm{~mm}$ when the local lengths are $2500 \mathrm{~mm}, 3250 \mathrm{~mm}$, and $4000 \mathrm{~mm}$, respectively.
The function of the position with a maximum of radiation flux has been obtained according to the simulation results in this paper.

(3) The results show that the radiation flux distribution of cylindrical receiver has the best performance in all four receivers, which will result in a higher efficiency of the system.

This paper aims to know the characteristic of radiation flux distribution for the receiver in different focal lengths 


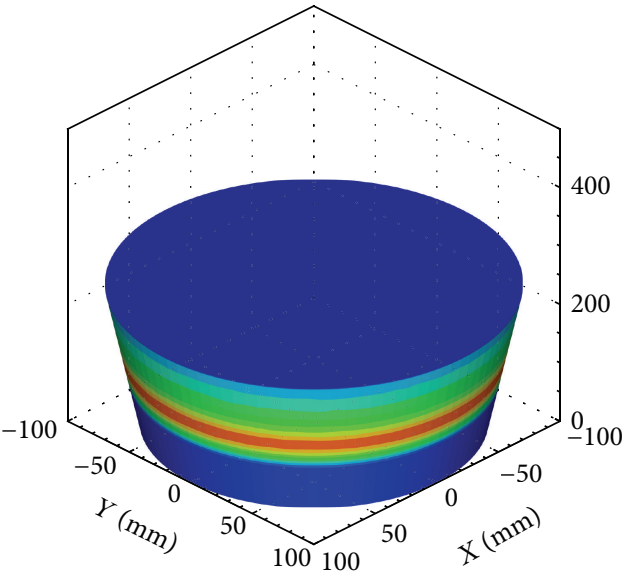

(a) Frustum

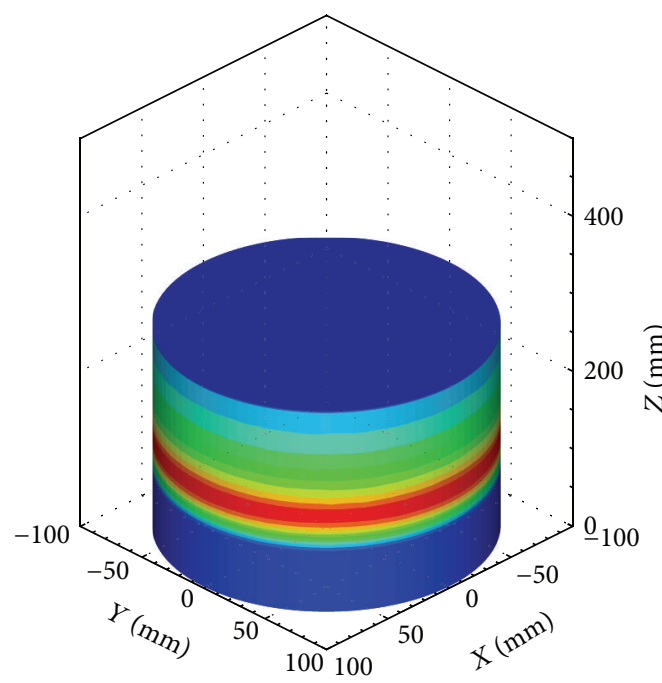

(c) Cylindrical

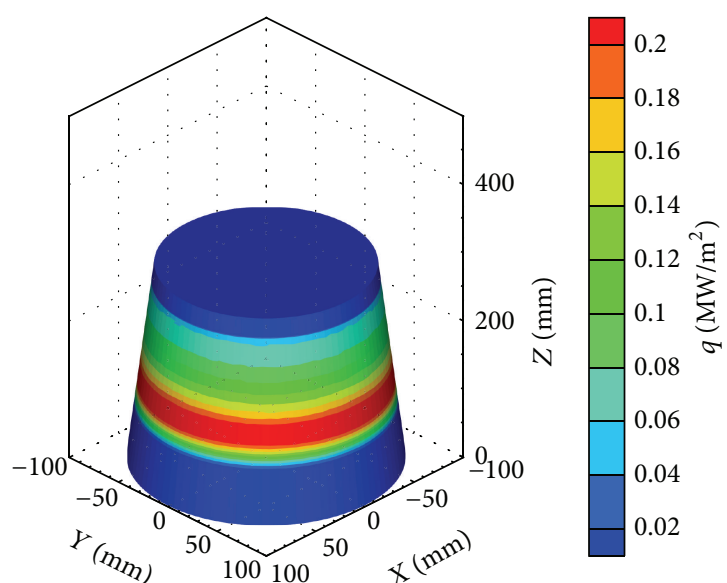

(b) Inverted frustum

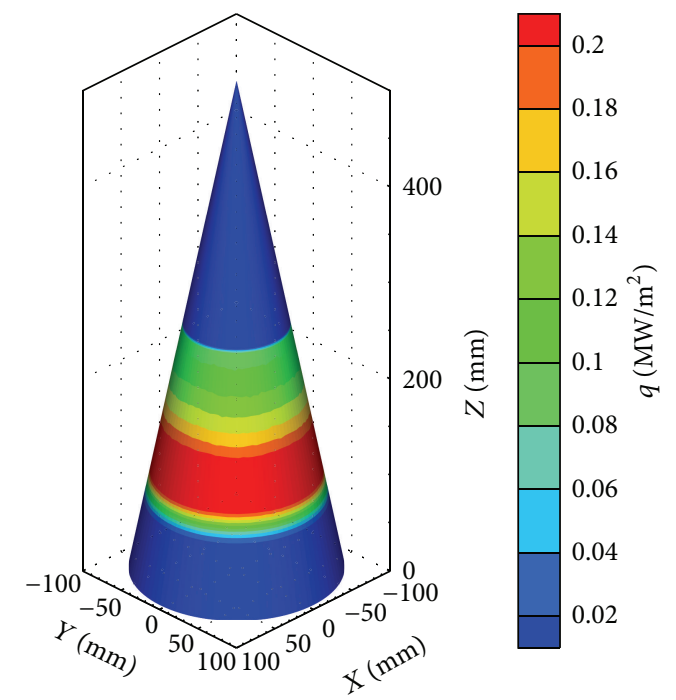

(d) Conical

FIGURE 6: Radiation flux distribution based on equal area-radius method.

and geometrical configurations and make a starting point to motivate future investigation in this field.

\section{Conflict of Interests}

The authors declare that there is no conflict of interests regarding the publication of this paper.

\section{Acknowledgments}

This work is supported by the National Natural Science Foundation of China (nos. 51406033 and 21306022), University Nursing Program for Young Scholars with Creative Talents in Heilongjiang Province (no. UNPYSCT-2015075), and the Natural Science Foundation of Heilongiiang Province (no. LC2012C35). Besides, a very special acknowledgement is made to the editors and referees who made important comments to improve this paper.

\section{References}

[1] J. T. Liu, M. Li, Q. F. Yu, and D. L. Ling, "A novel parabolic trough concentrating solar heating for cut tobacco drying system," International Journal of Photoenergy, vol. 2014, Article ID 209028, 10 pages, 2014.

[2] F. Al-Amri and T. K. Mallick, "Effects of nonuniform incident illumination on the thermal performance of a concentrating triple junction solar cell," International Journal of Photoenergy, vol. 2014, Article ID 642819, 12 pages, 2014.

[3] Q. Mao, Y. Shuai, and Y. Yuan, "Study on radiation flux of the receiver with a parabolic solar concentrator system," Energy Conversion and Management, vol. 84, pp. 1-6, 2014.

[4] Q. Mao, Y. Yuan, and Y. Shuai, "Effects of atmospheric aerosol on the direct normal irradiance on the earth's surface," International Journal of Hydrogen Energy, vol. 39, no. 12, pp. 6364-6370, 2014.

[5] M. Qianjun, X. Ming, S. Yong, and Y. Yuan, "Study on solar photo-thermal conversion efficiency of a solar parabolic dish 
system," Environmental Progress and Sustainable Energy, vol. 33, no. 4, pp. 1438-1444, 2014.

[6] Q. Mao, M. Xie, and H. Tan, "Effects of material selection on the radiation flux of a tube receiver in a dish solar system," Heat Transfer Research, vol. 45, no. 4, pp. 339-347, 2014.

[7] K. S. Reddy and G. Veershetty, "Viability analysis of solar parabolic dish stand-alone power plant for Indian conditions," Applied Energy, vol. 102, pp. 908-922, 2013.

[8] Z. Li, D. Tang, J. Du, and T. Li, "Study on the radiation flux and temperature distributions of the concentrator-receiver system in a solar dish/Stirling power facility," Applied Thermal Engineering, vol. 31, no. 10, pp. 1780-1789, 2011.

[9] H. Singh and P. C. Eames, "A review of natural convective heat transfer correlations in rectangular cross-section cavities and their potential applications to compound parabolic concentrating (CPC) solar collector cavities," Applied Thermal Engineering, vol. 31, no. 14-15, pp. 2186-2196, 2011.

[10] J. Ji, C. Guo, W. Sun, W. He, Y. Wang, and G. Li, "Experimental investigation of tri-functional photovoltaic/thermal solar collector," Energy Conversion and Management, vol. 88, pp. 650656, 2014.

[11] J. Ji, Y. Wang, W. Yuan, W. Sun, W. He, and C. Guo, "Experimental comparison of two PV direct-coupled solar water heating systems with the traditional system," Applied Energy, vol. 136, pp. 110-118, 2014.

[12] J. Jie, J. Cai, W. Huang, and Y. Feng, "Experimental study on the performance of solar-assisted multi-functional heat pump based on enthalpy difference lab with solar simulator," Renewable Energy, vol. 75, pp. 381-388, 2015.

[13] L. Guiqiang, P. Gang, S. Yuehong, J. Jie, and S. B. Riffat, "Experiment and simulation study on the flux distribution of lens-walled compound parabolic concentrator compared with mirror compound parabolic concentrator," Energy, vol. 58, pp. 398-403, 2013.

[14] G. Li, G. Pei, J. Ji, and Y. Su, "Outdoor overall performance of a novel air-gap-lens-walled compound parabolic concentrator (ALCPC) incorporated with photovoltaic/thermal system," Applied Energy, vol. 144, pp. 214-223, 2015.

[15] Y. Shuai, X. Xia, and H. Tan, "Radiation performance of dish solar concentrator/cavity receiver systems," Solar Energy, vol. 82, no. 1, pp. 13-21, 2008.

[16] A. M. Clausing, "An analysis of convective losses from cavity solar central receivers," Solar Energy, vol. 27, no. 4, pp. 295-300, 1981.

[17] A. M. Clausing, "Convective losses from cavity solar receiverscomparisons between analytical predictions and experimental results," Journal of Solar Energy Engineering, Transactions of the ASME, vol. 105, no. 1, pp. 29-33, 1983.

[18] K. Nithyanandam and R. Pitchumani, "Cost and performance analysis of concentrating solar power systems with integrated latent thermal energy storage," Energy, vol. 64, pp. 793-810, 2014.

[19] M. J. Emes, M. Arjomandi, and G. J. Nathan, "Effect of heliostat design wind speed on the levelised cost of electricity from concentrating solar thermal power tower plants," Solar Energy, vol. 115, pp. 441-451, 2015.

[20] N. B. Desai and S. Bandyopadhyay, "Optimization of concentrating solar thermal power plant based on parabolic trough collector," Journal of Cleaner Production, vol. 89, pp. 262-271, 2014.
[21] Z. Cheng, Y. He, and F. Cui, "Studies on concentrating solar collectors with a new modelling method and unified MCRT code," Chinese Science Bulletin, vol. 57, no. 22, pp. 2127-2136, 2012 (Chinese).

[22] J. B. Fang, J. J. Wei, X. W. Dong, and Y. S. Wang, “Thermal performance simulation of a solar cavity receiver under windy conditions," Solar Energy, vol. 85, no. 1, pp. 126-138, 2011.

[23] T. H. Ping and M. Lallemand, "Transient radiative-conductive heat transfer in flat glasses submitted to temperature, flux and mixed boundary conditions," International Journal of Heat and Mass Transfer, vol. 32, no. 5, pp. 795-810, 1989.

[24] T. Heping, B. Maestre, and M. Lallemand, "Transient and steady-state combined heat transfer in semi-transparent materials subjected to a pulse or a step irradiation," Journal of Heat Transfer, vol. 113, no. 1, pp. 166-173, 1991.

[25] F. Wang, Y. Shuai, H. Tan, and C. Yu, “Thermal performance analysis of porous media receiver with concentrated solar irradiation," International Journal of Heat and Mass Transfer, vol. 62, no. 1, pp. 247-254, 2013.

[26] F. Wang, R. Lin, B. Liu, H. Tan, and Y. Shuai, "Optical efficiency analysis of cylindrical cavity receiver with bottom surface convex," Solar Energy, vol. 90, pp. 195-204, 2013.

[27] F. Wang, Y. Shuai, H. Tan, and L. Gong, "Proposal of the shape layout of trapezoidal cavity receiver to improve the optical efficiency," Heat Transfer Research, vol. 46, no. 5, pp. 429-446, 2015. 

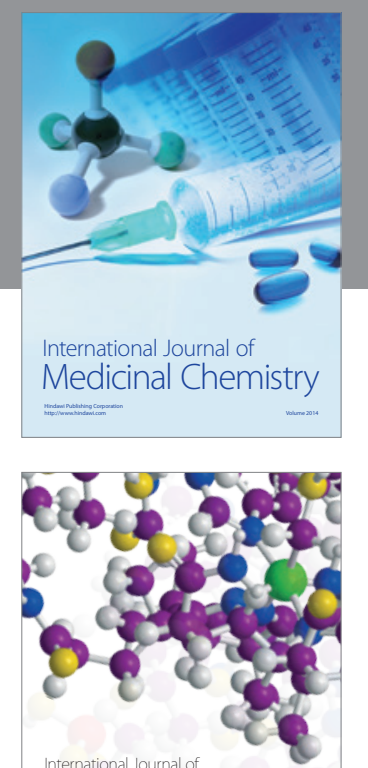

\section{Carbohydrate} Chemistry

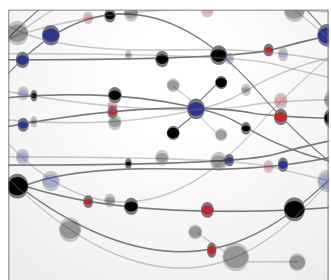

The Scientific World Journal
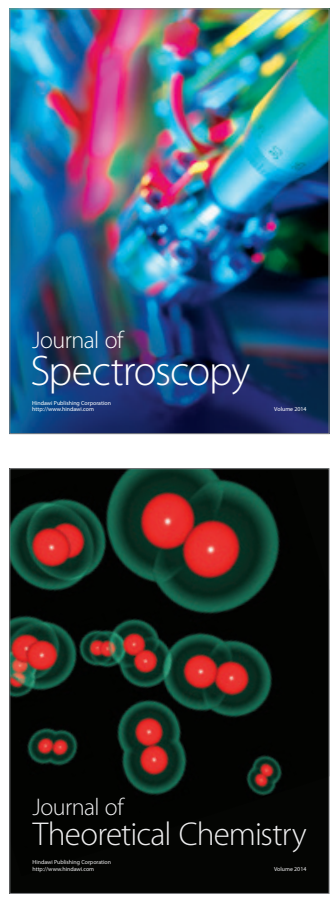
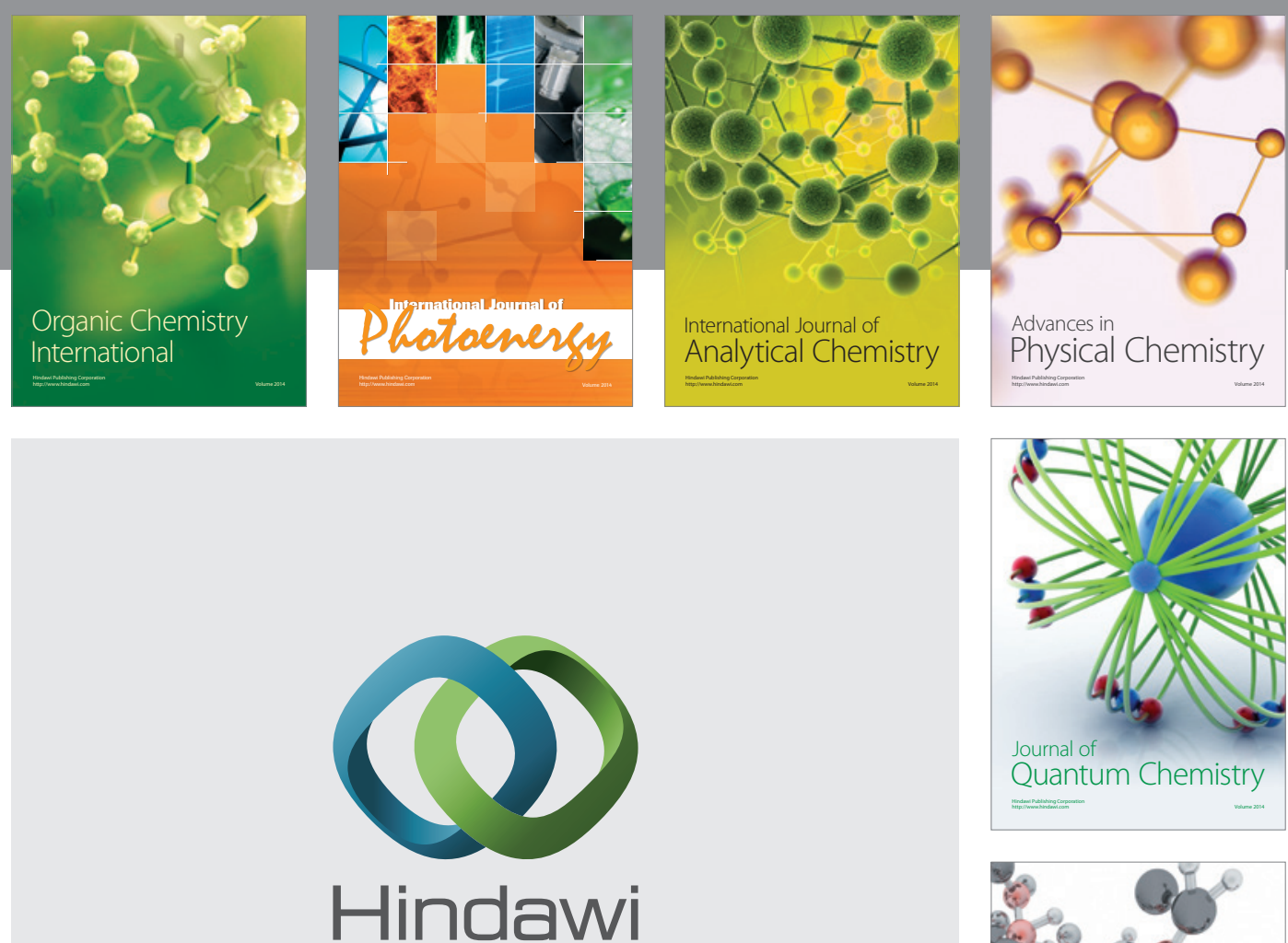

Submit your manuscripts at

http://www.hindawi.com

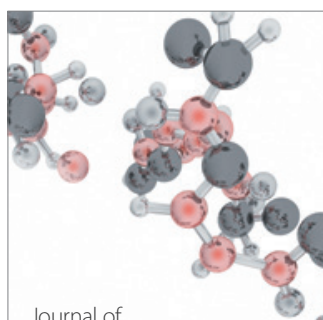

Analytical Methods

in Chemistry

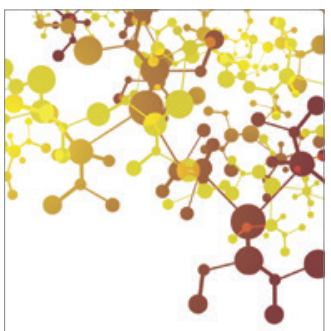

Journal of

Applied Chemistry

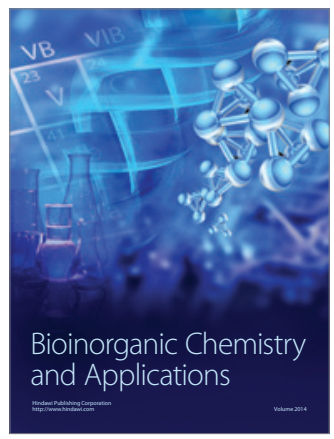

Inorganic Chemistry
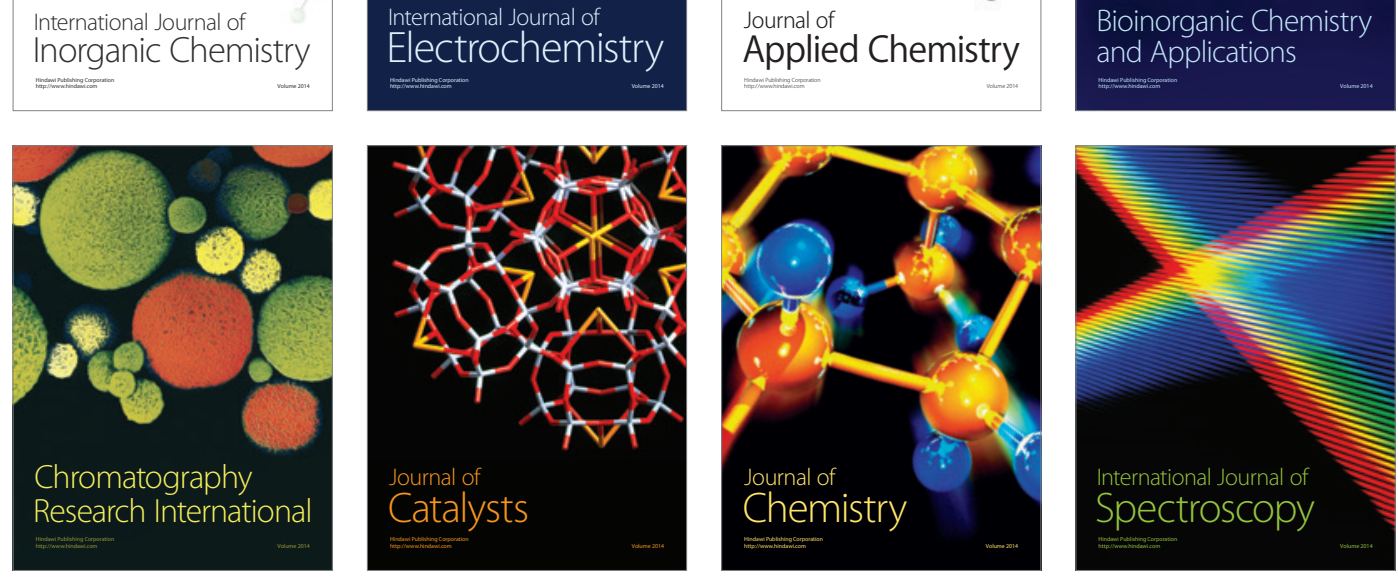